\section{ESO countries bury hatchet over new optical telescope}

Munich. Sharp differences over the plans and costs of what will eventually be the world's largest optical telescope, the Very Large Telescope (VLT), to be built at Mount Paranal in northern Chile, have been resolved by the member states of the European Southern Observatory.

As a result, construction work on the infrastructure for the VLT will begin as planned next month. Installation of the first of the four main 8.2-metre telescopes making up the core of the VLT is due for completion in late 1996 or early 1997 , and of all four by 2000 .

But plans have been postponed to link the four telescopes into the VLT Interferometer (VLTI). Also delayed will be installation of three smaller outlying telescopes and their associated instrumentation which, together with the original telescopes, will form VLT Interferometer Sub-Array (VISA).

Under original plans approved in 1987, all seven telescopes were to have been built as a single project, and the whole system would have come into operation in 2001 . Since then, however, tension has grown over an anticipated 25 per cent increase in its estimated costs over the initial figure of DM463 million (US\$275 million).

One reason for the increase has been demands from astronomers for increasingly sophisticated equipment, such as the 'adaptive optics', a French innovation allowing a small fast-moving mirror to compensate for distortions caused by air turbulence.

The additional costs had led to growing complaints from several of the eight countries which contribute to ESO. France and Italy were particularly vocal. Indeed France recently argued that, in order to keep within original estimates, few months. perhaps longer. lion) as planned to DM123 million. of success." the number of main telescopes should be reduced to three, or perhaps even two.

In the light of these complaints, a new construction schedule was agreed unanimously by the ESO council at the beginning of December. This will allow the VLT itself to begin observation by early 1997; indeed the opportunity to concentrate on a narrower range of targets may allow the date to be pulled forward by a

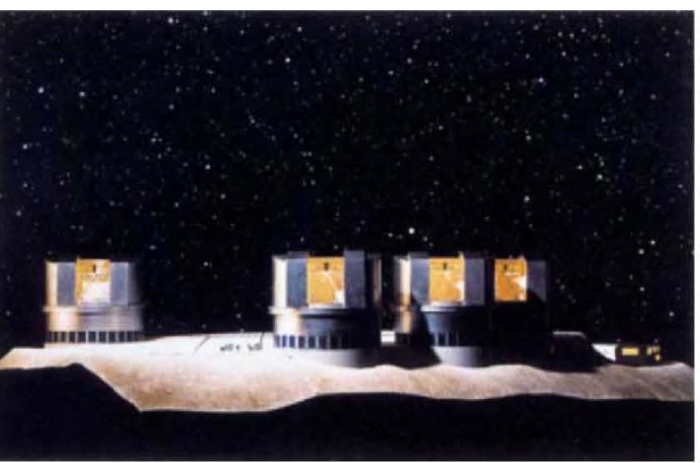

rtist's model of the Very Large Telescope (VLT)

Work will also begin on foundations for the other equipment. But no industrial contracts will be signed for this equipment for at least another two years, and

Stretching out the overall construction means that the ESO's budget contributions from its member states next year will fall from $\$ 142$ million (US\$84 mil-

Experiments with the complete system will now be delayed until well into the next decade, frustrating astronomers who had hoped it would be in operation earlier. But Riccardo Giacconi, the director general of ESO, says he is not unduly worried. "We were trying to do too much in a situation where money is tight," says Giacconi. "We now have a better chance

Alison Abbott

\section{Pay battle threatens fusion research}

Oxford. In a bid to end a long-standing dispute over the treatment of British scientists working for the Joint European Torus (JET) in Oxfordshire, the European Parliament has voted to withhold ECU59 million (US\$67 million) from the European commission's fusion budget for 1994 until the dispute is resolved.

The parliament is backing attempts by British staff at JET to receive the same salaries and future job opportunities as those from other European states. The

\section{US admits to use of humans in radiation experiments}

Washington. Administration officials met at the White House this week to coordinate a mammoth inquisition into radiation experiments that have been conducted in the United States since the Second World War.

The search for details on all such experiments will involve a number of government agencies. It is sure to embarrass parts of the scientific community, although many scientists and ethicists said last week that they welcomed the scrutiny.

The interagency initiative follows recent moves by Hazel O'Leary, the Secretary of Energy, to re-examine controversial radiation experiments conducted on human subjects by her own department and its predecessor, the Atomic Energy Commission.

O'Leary has promised to compensate up to 800 known subjects of the experiments and, sensing a public tide in her favour, has opened up a telephone hotline for people claiming to have information about such tests.

Her actions have opened the floodgates to a host of stories - many previously reported to little public response - of experiments conducted in the period 1945-75 which subjected people to varying degrees radiation, often without their consent.

O'Leary has appointed Dr Ruth Faden of Johns Hopkins University to head an advisory task force to review material from inside the department and from the hotline.

As stories of sometimes gruesome experiments involving children, servicemen, prisoners and the mentally handicapped sweep across America's television screens - many attributed to researchers at top institutions such as Harvard and the Massachusetts Institute of Technology scientists are deeply divided over the implications of the affair.

Some senior scientists believe that the ethical transgressions in many of the experiments were minor by the standards of the time, and that the whole field of biomedical research has in any case been transformed for the better since the experiments took place.

But others are less sanguine about what they see as the central role of the scientific establishment in allowing the experiments to proceed in the first place. Dr David Egilman, a physician at Brown University, Rhode Island, backs an investigation by the American Public Health Association: "That's the only organization with clean hands," he says.

Colin Macilwain 